\title{
Improvement of Enzymatic Stability and Catalytic Efficiency of Recombinant Fusariumoxysporum Trypsin with Different N-Terminal Residues Produced by Pichiapastoris
}

\author{
Ning Yang ${ }^{1,2}$, Zhenmin Ling ${ }^{1,2}$, Liang Peng ${ }^{1,2}$, Yanlai Liu ${ }^{1}$, Pu Liu ${ }^{1,2}$, Kai Zhang ${ }^{1,2}$, Aman ${ }^{1,2}$, Juanjuan Shi ${ }^{1,2}$, and \\ Xiangkai Li ${ }^{1,2 *}$ \\ ${ }^{1}$ School of Life Sciences, Lanzhou University, Lanzhou 730000, P.R. China \\ ${ }^{2}$ Ministry of Education, Key Laboratory of Cell Activities and Stress Adaptations, Lanzhou 730000, P.R. China
}

Received: April 16, 2018

Revised: June 27, 2018

Accepted: July 4, 2018

First published online July 12, 2018

${ }^{*}$ Corresponding author Phone: +86-931-8912560; Fax: +86-931-8921561;

E-mail: xkli@lzu.edu.cn

pISSN 1017-7825, eISSN 1738-8872

Copyright@ 2018 by

The Korean Society for Microbiology and Biotechnology
Fusarium oxysporum trypsin (FOT) is a fungal serine protease similar to mammal trypsin. The FOT could be successfully expressed in Pichiapastoris by engineering the natural propeptide APQEIPN. In this study, we constructed two recombinant enzymes with engineered amino acid sequences added to the $\mathrm{N}$-terminus of FOT and expressed in P. pastoris. The N-terminal residues had various effects on the structural and functional properties of trypsin. The FOT, and the recombinants TE (with peptide YVEF) and TS (with peptide YV) displayed the same optimum temperature $\left(40^{\circ} \mathrm{C}\right)$ and $\mathrm{pH}(8.0)$. However, the combinants TE and TS showed significantly increased thermal stability at $40^{\circ} \mathrm{C}$ and $50^{\circ} \mathrm{C}$. Moreover, the combinants TE and TS also showed enhanced tolerance of alkaline $\mathrm{pH}$ conditions. Compared with those of wildtype FOT, the intramolecular hydrogen bonds and the cation $\pi$-interactions of the recombinants TE and TS were significantly increased. The recombinants TE and TS also had significantly increased catalytic efficiencies (referring to the specificity constant, $k_{c a t} / K_{m}$ ), 1.75fold and 1.23-fold than wild-type FOT. In silico modeling analysis uncovered that the introduction of the peptides YVEF and YV resulted in shorter distances between the substrate binding pocket (D174, G198, and G208) and catalytic triad (His42, Asp102, and Ser180), which would improve the electron transfer rate and catalytic efficiency. In addition, N-terminal residues modification described here may be a useful approach for improving the catalytic efficiencies and characteristics of other target enzymes.

Keywords: Trypsin, N-terminal peptide, catalytic efficiency, Pichiapastoris

\section{Introduction}

Fusarium oxysporum trypsin (FOT) (E.C. 3.4.21.4) is a serine protease that cleaves peptide bonds at the carboxylterminal end of lysine and arginine residues [1]. This enzyme is mainly obtained from mammalian pancreatic tissue and applied in leather bating, clinical medicine fields, food processing and bioethanol industries [2-4]. However, there are many problems restricting the application of the enzyme, such as raw material limitations, potential cross-infection, dangers to mammal immunogenicity and the high cost of purifying the enzyme mixture $[3,5,6]$.
Consequently, increasing attention is being devoted to decreasing the autocatalysis of trypsin and improving the catalytic performance and stability of enzymes [7-9].

Protein heterologous expression has emerged as an effective tool to overcome the limitations of natural enzymes $[9,10]$. Common expression systems for altered proteins include the E. coli and P. pastoris expression systems [11, 12]. Trypsins from humans, cows, fish, sardines and shrimp have been expressed successfully in the E. coli system by molecular biotechnology [11-13]. However, the yield of these recombinant trypsins were low; otherwise the enzymes needed to be activated with enterokinase and 


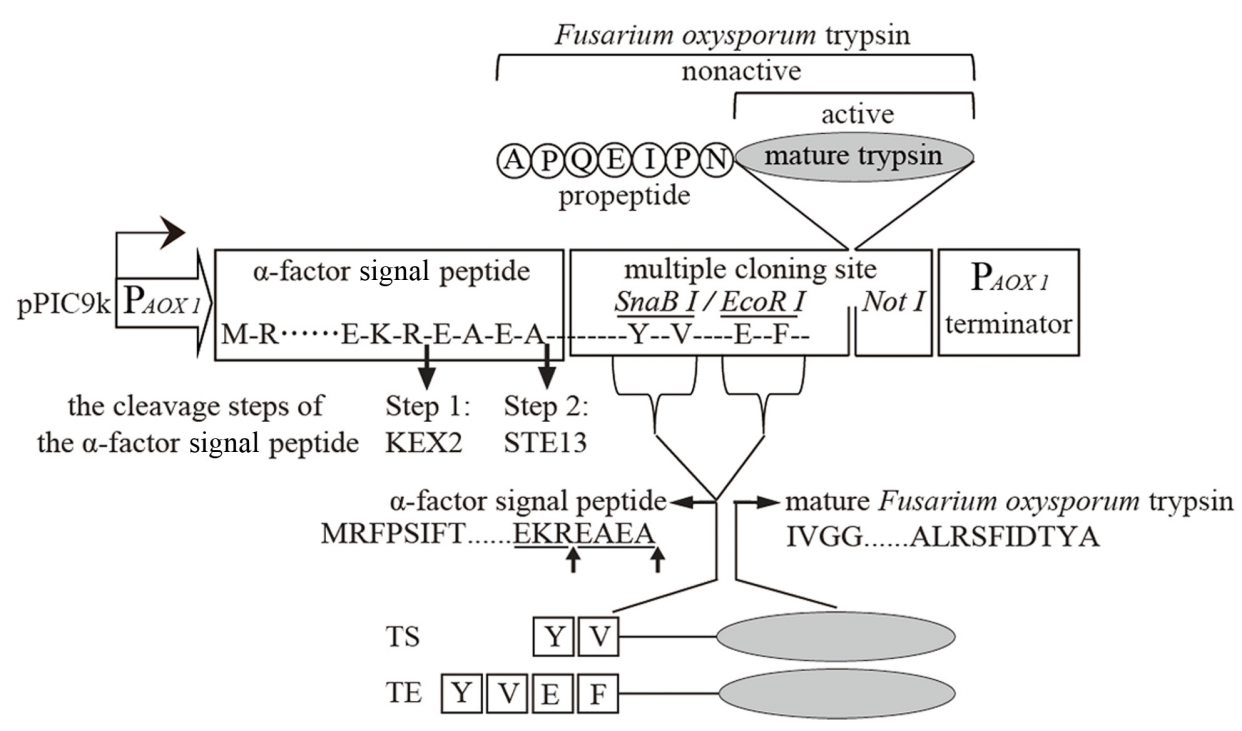

Fig. 1. Schematic representations of vector construction, composition of wild-type FOT and the recombinants TS and TE with the peptide residues YV and YVEF, respectively.

The cleavage process of the a-factor signal peptide.

even formed inclusion bodies [11-14]. The methylotrophic yeast Pichia pastoris has been widely used for producing target proteins at high levels, especially secreted proteins. The P.pastoris system has been used to harvest soluble trypsin and improve its catalytic efficiency and thermal stability $[2,15]$. Hence, the $P$. pastoris expression system is considered an alternative trypsin expression system.

Introduction of peptides to the N-terminal of enzymes improves the expression of proteins and their catalytic performance and alters their structure in P. pastoris [7, 9, 16]. The sequence of natural propeptide of FOT is APQEIPN, and the $\alpha$-factor signal peptide is cleaved by the peptidases KEX2 and STE13 (Fig. 1). Recently, a study indicated that $\mathrm{N}$-terminal residues with different amino acids affected the activity of a trypsin from Streptomyces griseus [8]. When the N-terminal amino acid residues were the exogenous peptide YVEF, the catalytic efficiencies of trypsin on the substrates BAPNA and BAEE were increased by 3.1 and 5.5 times, respectively, in P. pastoris GS115 [8, 17]. In addition, a previous study showed that rationally engineering the peptides of the $\mathrm{N}$-terminus might improve the properties of trypsin, suggesting the importance of $\mathrm{N}$-terminal peptides for enzyme expression and activity [7]. Most recently, Zhang et al. (2018) developed a novel strategy that significantly improved the active production of protein and the stability of enzyme activity, indicating that the amino acid residues of the $\mathrm{N}$-terminus offered an attractive approach for increasing the properties of the target enzymes [9]. The X-ray structure and enzymatic characteristics of trypsin from $F$. oxysporum have been studied [18, 19]. However, there are few reports regarding heterologous expression of FOT. Therefore, we reasoned that it may be possible to enhance the stability or catalytic efficiency of this protein by introducing amino acids at its $\mathrm{N}$-terminus. To the best of our knowledge, there have been no reports of such modifications to trypsin from F. oxysporum produced by $P$. pastoris.

In this study, we investigated whether the introduction of amino acid residues to the $\mathrm{N}$-terminus of trypsin could enhance its stability and catalytic efficiency. Specifically, the non-natural peptides YVEF and YV were added to the N-terminus of trypsin from F. oxysporum through digestion with the restriction enzymes EcoRI and NotI or SnaBI and NotI in P.pastoris, respectively (Fig. 1). The biochemical properties, including specific activity, catalytic efficiency, $\mathrm{pH}$ stability and thermal stability of the recombinant enzymes were characterized and compared with those of wild-type FOT. The recombinant proteins were observed to have increased catalytic efficiency, thermal stability and $\mathrm{pH}$ tolerance. A three-dimensional (3-D) structural model of these recombinant proteins was obtained using in silico simulation and compared with that of wild-type FOT to uncover the structural changes responsible for the improved characteristics. 
Table 1. Strains, plasmids and primers used in this study.

\begin{tabular}{|c|c|c|}
\hline Strains and plasmids & Genotypes and characteristics & References \\
\hline \multicolumn{3}{|l|}{ Strains } \\
\hline E. coli JM109 & F'traD36 proA+B+lacI $\Delta$ (lacZ) M15/ $\Delta$ (lac-proAB) glnV44e14- gyrA96 recA1 relA1 endA1 thi hsdR17 & Lab stock \\
\hline P. pastoris GS115 & his4 Mut+His - (aox1+, aox2+) & Lab stock \\
\hline \multicolumn{3}{|l|}{ Plasmids } \\
\hline pPIC9k & HIS4 Amp ${ }^{r}$ or Kan ${ }^{r}$ & Lab stock \\
\hline \multicolumn{3}{|l|}{ Primers $\left(5^{\prime} \rightarrow 3^{\prime}\right)$} \\
\hline T-SnaBF & CCGTACGTAATCGTTGGTGGAACCTCTGC & This study \\
\hline T-EcoRF & CCGGAATTCATCGTTGGTGGAACCTCTGC & This study \\
\hline T-NotR & ATAAGAATGCGGCCGCAGCATAAGTGTCAATGAAGGATCTC & This study \\
\hline $5^{\prime} \mathrm{AOX}$ & GACTGGTTCCAATTGACAAGC & This study \\
\hline 3'AOX & GCAAATGGCATTCTGACATCC & This study \\
\hline$\alpha$-factor & TACTATTGCCAGCATTGCTGC & This study \\
\hline
\end{tabular}

\section{Materials and Methods}

\section{Construction of Expression Vectors and Transformation in P. pastoris}

The recombinant expression vectors were constructed using the corresponding primers (Table 1). The production and expression vector pPIC9K was treated with the restriction enzymes EcoRI and NotI or SnaBI and NotI to introduce the N-terminal residues YVEF and YV, respectively. Then, the ligated products were transformed into $E$. coli JM109. The expression vectors and strains were identified by bacterial colony PCR and DNA sequencing. The amino acid sequences were aligned by BLASTp and the ClustalW program.

The recombinant plasmids were linearized by SalI and then transformed into P. pastoris GS115 by electric transformation $(5.6 \mathrm{~ms}$, $3000 \mathrm{~V})$. Transformants were screened on MD plates containing a different concentration of Genetic in 418 and identified by colony PCR with primers 5'AOX and 3'AOX. The empty vector pPIC9K was used as a negative control.

\section{Microorganisms and Growth Conditions}

Wild-type FOT was produced using F. oxysporum provided by Taishan Medical University. The F. oxysporum was cultured in a $500 \mathrm{ml}$ flask supplied with a $100 \mathrm{ml}$ buffered suspension of potatoincluding $2 \%$ glucose at $30^{\circ} \mathrm{C}$ and $110 \mathrm{rpm}$. The recombinant strains were cultured in a $500 \mathrm{ml}$ baffled flask with $100 \mathrm{ml}$ culture broth containing glycerol at $30^{\circ} \mathrm{C}$ and $180 \mathrm{rpm}$. When the $\mathrm{OD}_{600}$ value reached 2.0, the cells were harvested and resuspended in $100 \mathrm{ml}$ of culture broth with methanol. The culture broth was shaken at $30^{\circ} \mathrm{C}$ and $180 \mathrm{rpm}$ and supplemented with $1.2 \%$ methanol every $24 \mathrm{~h}$ to induce the expression of the recombinant proteins. These data were analyzed using the Origin software (OriginPro8.0, USA), and each experiment had three replicates. The error bars represent the standard deviation of the mean (SD).

\section{Purification of Proteins}

The fermentation cultures of TE and TS were collected after being induced with methanol and centrifuged at 5,800 $\mathrm{g}$ for $15 \mathrm{~min}$, and then filtered using a $0.22-\mu \mathrm{m}$ Millex-GP. The sample was loaded onto a HiTrap Benzamidine FF column $(\mathrm{U} 1.6 \times 2.5 \mathrm{~cm}$, GE Healthcare, catalog number 17-5144-01, made in Sweden) that was equilibrated with buffer A (50 mM Tris- $\mathrm{HCl}, \mathrm{pH} 8.0,0.5 \mathrm{M}$ $\mathrm{NaCl})$. The concentrated proteins were washed with buffer $\mathrm{B}$ (0.5 M NaCl, $10 \mathrm{mM} \mathrm{HCl}, \mathrm{pH} 2.0)$, and $60 \mu 11 \mathrm{M}$ Tris-HCl, pH 9.0, was added per $\mathrm{ml}$ of the fraction to be collected. Then, the column was eluted with $20 \%$ ethanol in $50 \mathrm{mM}$ acetate buffer ( $\mathrm{pH} 4.0$ ) at a rate of $4 \mathrm{ml} \cdot \mathrm{min}^{-1}$. The protein concentration was determined by a Beyotime Biotechnology, China.

\section{SDS-PAGE Analysis of Proteins}

The purified proteins were separately subjected to a $12 \%$ sodium dodecyl sulfate polyacrylamide gel and stained with Coomassie Brilliant Blue. The $20 \mu \mathrm{l}$ samples were pretreated by mixing with $5 \mu \mathrm{l}$ of $5 \mu \mathrm{l} \times$ SDS-PAGE loading buffer in a $200 \mu \mathrm{l}$ centrifuge tube. The samples were incubated at $100^{\circ} \mathrm{C}$ for $10 \mathrm{~min}$, and then each sample was loaded into a sample well.

\section{Determination of Protein Activity}

The amidase activities of the samples were estimated using Nabenzoyl-DL-arginine- $p$-nitroanilide (BAPNA) as a substrate, which was dissolved in N,N-Dimethylformamide (DMF). The amidase analysis was performed as follows: $100 \mu \mathrm{l}$ of sample solution was added to $900 \mu \mathrm{l}$ Tris- $\mathrm{HCl}$ buffer $\left(50 \mathrm{mM}, \mathrm{pH} 8.0 ; 2 \mathrm{mmol} \mathrm{CaCl}_{2}\right.$; $0.25 \mathrm{mM}$ BAPNA). The change in absorbance at $410 \mathrm{~nm}$ was monitored with a U-3900H spectrophotometer every $10 \mathrm{sec}$; the data were recorded and reported subsequently. One BAPNA unit $(\mathrm{U} / \mathrm{ml})$ of trypsin was defined as the total enzyme required to produce an absorbance increase of 0.1 under the above conditions. The amidase activity was calculated according to Eq. (1): 


$$
\text { BAPNA unit }(\mathrm{U} / \mathrm{ml})=\frac{\Delta \mathrm{A} 410 / \mathrm{min} \times \mathrm{df}}{0.1}
$$

Effects of Temperature and $\mathrm{pH}$ on Trypsin Activity and Stability

The optimum temperature for trypsin activity was studied by measuring the sample from $30^{\circ} \mathrm{C}$ to $90^{\circ} \mathrm{C}$. The thermal stability of trypsin was studied by incubating the sample at $40^{\circ} \mathrm{C}$ every $30 \mathrm{~min}$ and $50^{\circ} \mathrm{C}$ every $5 \mathrm{~min}$, and then detecting the amidase activity of those treated proteins. To determine the optimum $\mathrm{pH}$ for trypsin activity, the purified protein was incubated in BrittonRobinson Buffer ( $\mathrm{pH}$ 2.0-12.0). The buffer system used was $40 \mathrm{mM} \mathrm{H}_{3} \mathrm{BO}_{3}, 40 \mathrm{mM} \mathrm{H}_{3} \mathrm{PO}_{4}$, and $40 \mathrm{mM} \mathrm{CH}_{3} \mathrm{COOH}$. The $\mathrm{pH}$ stability of enzyme was also determined at $\mathrm{pH}$ from 2.0 to 12.0 . Before these samples were measured, the proteins were incubated in Britton-Robinson Buffer (2.0-12.0) at $37^{\circ} \mathrm{C}$ for $1 \mathrm{~h}$. And then the enzyme activity was measured at $\mathrm{pH} 8.0$ at $37^{\circ} \mathrm{C}$. It is defined that the highest residual activity at a confirmed $\mathrm{pH}$ was $100 \%$.

\section{Determination of Kinetic Parameters}

Kinetic parameters toward BAPNA were estimated with $50 \mathrm{mM}$ Tris- $\mathrm{HCl}$ buffer $(\mathrm{pH} 8.0)$ at $37^{\circ} \mathrm{C}$. For Michaelis-Menten kinetics, 8 concentrations $(0.05,0.1,0.15,0.2,0.25,0.3,0.35$, and 0.4$)$ of BAPNA were used. The enzyme activity was then detected by UV-visible spectrophotometer (Shimadzu, U-3900H, Japan) and data were analyzed using the software of GraphPad Prism6.

\section{Template Selection for Construction of the 3D Model Structure}

The X-ray crystal structure of FOT (PDB ID: 1xvo) was downloaded from the RCSB Protein Data Bank (http://www.pdb.org/pdb/ home/home.do). In this paper, we use the original residue numbers reported in the literature and the 1 xvo PDB file, and the corresponding residue numbers in the 1xvo PDB file are not shifted by adding extra amino acids at the $\mathrm{N}$-terminus. Because of the lack of detailed and mechanistic knowledge about propeptides and trypsinogen, the structure of FOT was used as the template for modeling. Stereochemical analysis of the structure was performed using the PROCHECK (http://nihserver.mbi.ucla.edu/ SAVS/) online server, and the final model, which displayed good geometry with less than $1 \%$ of residues in the disallowed region, was used in this study.

\section{Modeling Procedure for the Recombinants TE and TS}

The coordinates used for the molecular dynamics procedure were obtained from the previous modeling steps. The 3D model structure was constructed with the software NAMD with CHARMM force field (http://www.ks.uiuc.edu/Research/namd) [20]. $\mathrm{Na}^{+}$ was added to neutralize the system. The $\mathrm{pH} 7.0$ was set as default. The proteins were solvated in a cubic box consisting of TIP3P water molecules, and the box size was chosen by the criterion that the distance of protein atoms from the wall was greater than 10.0 A. An Ewald summation method named Particle Mesh Ewald (PME) was used for calculating the total electrostatic energy in a periodic box. Structure minimization was performed to remove any unexpected coordinate collisions and obtain local minima. The water box and the whole system were minimized using the descent method plus the conjugate gradient method. After minimization, system heating, equilibration and data sampling were carried out in turn. The system heating was performed gradually from $\mathrm{T}(\mathrm{k})=\mathrm{t}\left({ }^{\circ} \mathrm{C}\right)+273.15$ to the desired temperature in an NTV ensemble, followed by a further 150 ps simulation for equilibration and $3 \mathrm{~ns}$ or longer simulation for data sampling in an NTP ensemble. The temperatures were set as $\mathrm{T}(\mathrm{k})=\mathrm{t}\left({ }^{\circ} \mathrm{C}\right)+273.15$, respectively, at $1 \mathrm{~atm}$ pressure. Finally, the structural diagram was drawn with PyMOL software (http://pymol.sourceforge.net/).

\section{Parameter Calculation of the Protein Structure}

The simulated models of the trypsingen mutants also had structural parameters from primary sequence to tertiary structure, and the simulated mutants were further determined by these parameters. Among these parameters, the amino acids (primary structural parameter), intramolecular $\mathrm{H}$ bonds, ion pairs, cation $\pi$-interactions (secondary structural parameters), and secondary structure contents (tertiary structural parameter) are important for the investigation. The amino acids were calculated by Vector NTI software; the intramolecular $\mathrm{H}$ bonds were predicted by PyMol software (http:/ / pymol.sourceforge.net/); the cation $\pi$-interactions were predicted by the CaPTURE program online server ( http:/ / capture.caltech.edu/)[21].

\section{Results}

\section{Construction and Expression of FOT and Recombinant Proteins}

The recombinant plasmids pPIC9K/TE and pPIC9K/TS were constructed based on the genome of F. oxysporum trypsin in E. coli JM109. These constructed plasmids were confirmed and verified by colony PCR and sequencing, and then transformed into P. pastoris GS115 via electro transformation. The recombinant strains were successfully screened by resistance to different concentrations of G418. As shown in Fig. 2A, the trypsins were secreted into the culture medium, and their amidase activity increased with cell growth. The amidase activity of the recombinant proteins was significantly higher than that of wild-type FOT. The cell growth curves of the recombinant proteins and wild-type FOT were also determined. In addition, the supernatants were successfully purified for both recombinant trypsins (TE and TS) and FOT. The SDS-PAGE analysis showed that the proteins were approximately $25 \mathrm{kDa}$ in size (Fig. $2 \mathrm{~B}$ ) and the proteins were termed TE, TS, and FOT. As a result, the recombinant proteins including the peptides YVEF and YV introduced to the N-terminus of FOT were successfully constructed and were expressed in P. pastoris GS115. 
A

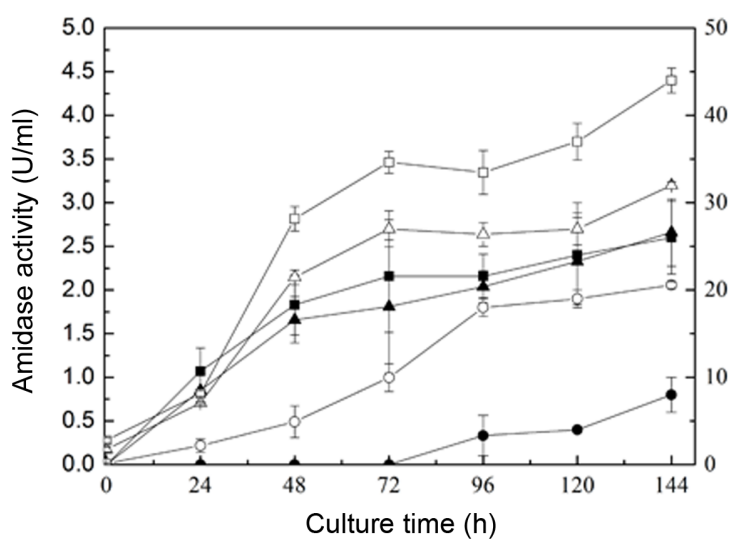

B

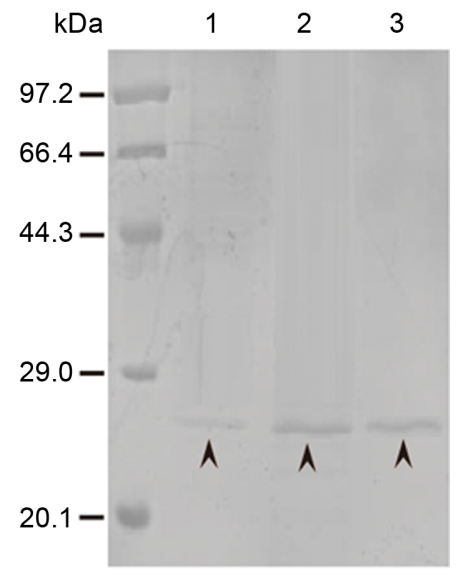

Fig. 2. (A) Characterization of the recombinant strains and F. oxysporum. The trypsin amidase of P. pastoris GS115-TS (filled squares), the trypsin amidase of P. pastoris GS115-TE (filled triangles), the trypsin amidase of F. oxysporum (filled circles), OD600 of $P$. pastoris GS115-TS (open squares), OD600 of $P$. pastoris GS115-TE (open triangles), OD600 of $F$. oxysporum (open circles). The culture conditions of the recombinant strains were $100 \mathrm{ml} / 500 \mathrm{ml}$ BMMY; temperature, $30^{\circ} \mathrm{C}$; agitation speed, $200 \mathrm{rpm}$. The culture conditions of $F$. oxysporum were PDA; $100 \mathrm{ml} / 500 \mathrm{ml}$; temperature, $30^{\circ} \mathrm{C}$; agitation speed, $100 \mathrm{rpm}$. (B) SDS-PAGE analysis of the purified FOT and the recombinants TE and TS. M, marker; lane 1, purified FOT; lane 2, purified TE; lane 3, purified TS.

\section{Increased Thermostability with the Peptides YVEF and YV}

The optimum temperatures for the enzymes were determined by measuring their activities after incubation at different temperatures (from $30^{\circ} \mathrm{C}$ to $80^{\circ} \mathrm{C}$ ). Thus, for this purpose, the recombinant trypsins and wild-type FOT were treated at different temperature parameters as shown in Fig. 3. The optimum temperature of all enzymes for activity was the same, $40^{\circ} \mathrm{C}$ (Fig. 3A). Whereas, recombinant trypsins displayed a wider range of temperature $\left(30^{\circ} \mathrm{C}-80^{\circ} \mathrm{C}\right)$ than that of wild-type FOT $\left(30^{\circ} \mathrm{C}-50^{\circ} \mathrm{C}\right)$. Moreover, the relative activity of wild-type FOT was dramatically decreased (10\%) at $50^{\circ} \mathrm{C}$ as compared to the combinant trypsins (Fig. 3B). Furthermore, the effects of temperature on trypsin stability were also determined. Compared with FOT, the recombinant trypsins exhibited enhanced thermal stability, especially TE with the peptide YVEF instead of FOT. When treated at $40^{\circ} \mathrm{C}$ for $270 \mathrm{~min}$, the recombinant TE with YVEF displayed the higher temperature tolerance than the wild type. The value of the TE relative activity was approximately 2 -fold that of FOT at the point of $270 \mathrm{~min}$. When treated at $50^{\circ} \mathrm{C}$ for $30 \mathrm{~min}$, the recombinant trypsin also displayed the higher temperature tolerance than that of FOT. Meanwhile, when treated at $50^{\circ} \mathrm{C}$ for $20 \mathrm{~min}$, the FOT retained only about $10 \%$ relative activity (Fig. 3B). These results demonstrated that the recombinant trypsins have higher tolerance and stability of temperature than FOT.

\section{Increased pH Stability with the Peptides}

The effects of $\mathrm{pH}$ on the activity of trypsin were determined in between $\mathrm{pH} 2.0$ and 12.0 in Britton-Robinson Buffer. As shown in Fig. 3C, the optimum $\mathrm{pH}$ for all trypsins was the same, $\mathrm{pH}$ 8.0. Moreover, the $\mathrm{pH}$ stability of TE and TS was higher than that of FOT (Fig. 3D). When treated at $\mathrm{pH} 12$ for $1 \mathrm{~h}$, the relative activity of the recombinant trypsin with peptide remained at least $50 \%$, while FOT retained approximately $10 \%$ residual activity under a confirmed $\mathrm{pH}$ condition (Fig. 3C). Meanwhile, the enzyme activity of TE, with the peptide YVEF, exhibited more stability than that of TS, with the peptide $\mathrm{YV}$, in the range of $\mathrm{pH}$ 8.0-12.0. These results demonstrated that the recombinant trypsins with the peptide YVEF and YV have higher $\mathrm{pH}$ tolerance than that of the FOT.

\section{Effects of the Peptide YVEF on Kinetic Parameters and Catalytic Efficiency}

The influence of the peptide YVEF on kinetic parameters and catalytic efficiency was comparatively analyzed with amidase activity on the substrate BAPNA. Table 2 showed the kinetic parameters and catalytic efficiency of FOT and the recombinant proteins. The specific activity of TE was higher (1.26-fold) than that of the FOT, whereas the specific activity of TS was almost the same as that of the FOT. The Michaelis constants ( $\mathrm{Km}$ values) of all recombinant proteins were consistent with that of FOT, indicating that the N- 
A

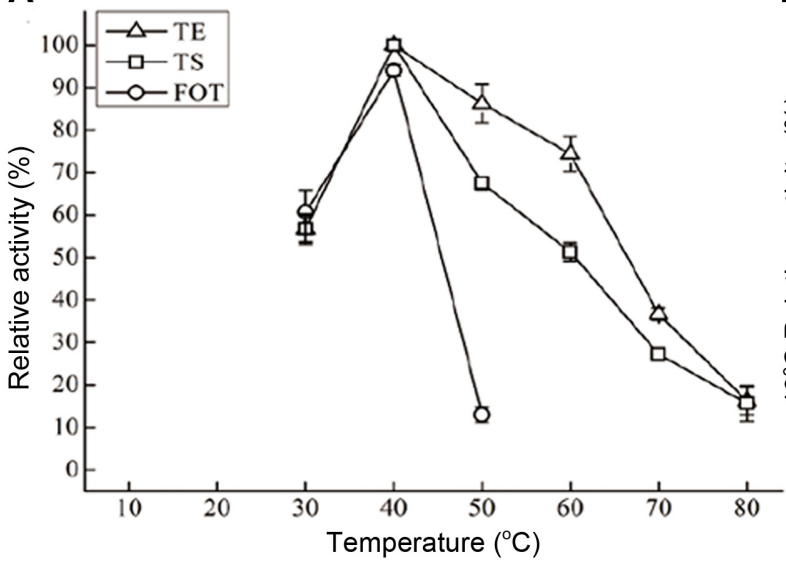

C

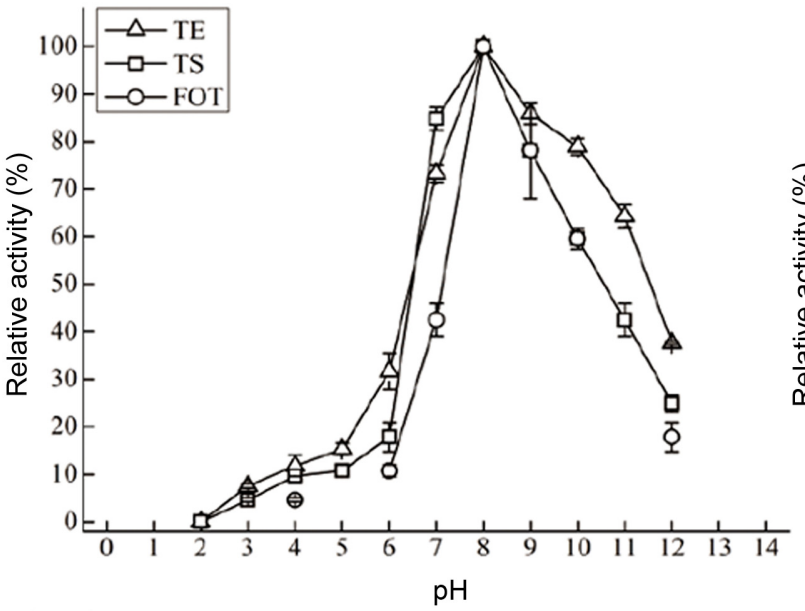

B

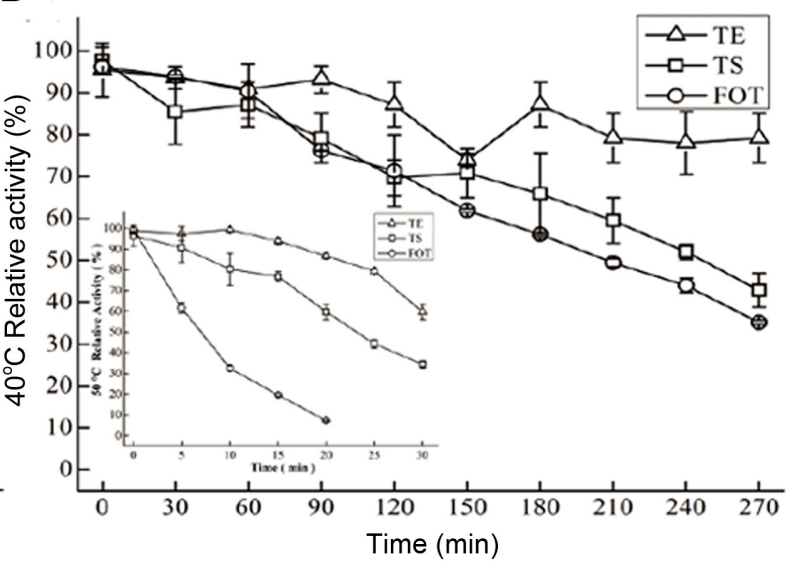

D

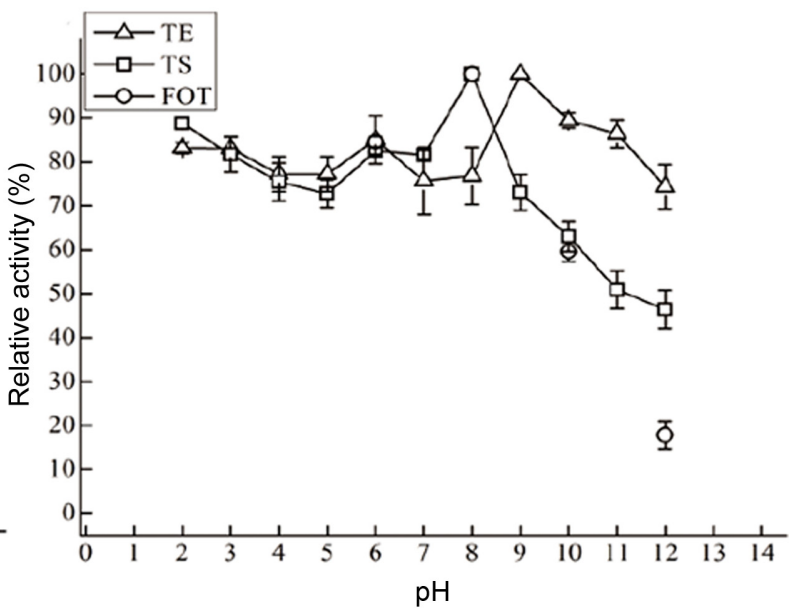

Fig. 3. Influence of temperature and $\mathrm{pH}$ on the activities of the recombinants TE and TS and wild-type FOT.

(A) Temperature kinetics of TE, TS, and FOT. (B) Thermostability of FOT, TE, and TS at $40^{\circ} \mathrm{C}$ and $50^{\circ} \mathrm{C}$. (C) $\mathrm{pH}$ kinetics of TE, TS, and FOT. (D) pH tolerance of TE, TS, and FOT.

terminal peptide had insignificant substrate binding ability. The catalytic constant $\left(k_{\text {cat }}\right)$ of TE $\left(1.719 \times 10^{3} \mathrm{~min}^{-1}\right)$ was higher than that of FOT $\left(0.947 \times 10^{3} \mathrm{~min}^{-1}\right)$; meanwhile, that of TS $\left(1.273 \times 10^{3} \mathrm{~min}^{-1}\right)$ was higher than that of FOT by 1.34 -fold. The $k_{\text {cat }} / K_{m}$ of TE $\left(0.5925 \times 10^{7}[\mathrm{~mol} \cdot 1 \cdot \mathrm{min}]^{-1}\right)$ was 1.74-fold that of FOT $\left(0.5925 \times 10^{7}[\mathrm{~mol} \cdot 1 \cdot \mathrm{min}]^{-1}\right)$, and that of
TS $\left(0.4163 \times 10^{7}[\mathrm{~mol} \cdot 1 \cdot \mathrm{min}]^{-1}\right)$ was higher than that of FOT. These results indicated that the recombinant proteins with the peptides YVEF and YV added to the N-terminus of trypsin significantly improved its catalytic constant $\left(k_{c a t}\right)$ and catalytic efficiency, especially in the presence of the residues YVEF.

Table 2. Enzyme properties of wild-type FOT and the recombinants TE and TS.

\begin{tabular}{|c|c|c|c|}
\hline Property & FOT & $\mathrm{TE}$ & TS \\
\hline Optimum pH & 8.0 & 8.0 & 8.0 \\
\hline Optimum $\operatorname{Tm}\left({ }^{\circ} \mathrm{C}\right)$ & 40 & 40 & 40 \\
\hline Specific activity $\left(\times 10^{2} \mathrm{U} \cdot \mathrm{mg}^{-1}\right.$, substrate BAPNA) & $0.50 \pm 0.02$ & $0.63 \pm 0.07$ & $0.55 \pm 0.07$ \\
\hline$K_{\mathrm{m}}\left(\times 10^{-4} \mathrm{~mol} \cdot \mathrm{l}^{-1}\right.$, substrate BAPNA $)$ & $2.804 \pm 0.06$ & $2.901 \pm 0.07$ & $3.058 \pm 0.09$ \\
\hline$k_{\text {cat }}\left(\times 10^{3} \mathrm{~min}^{-1}\right.$, substrate BAPNA $)$ & $0.947 \pm 0.02$ & $1.719 \pm 0.05$ & $1.273 \pm 0.05$ \\
\hline
\end{tabular}


A

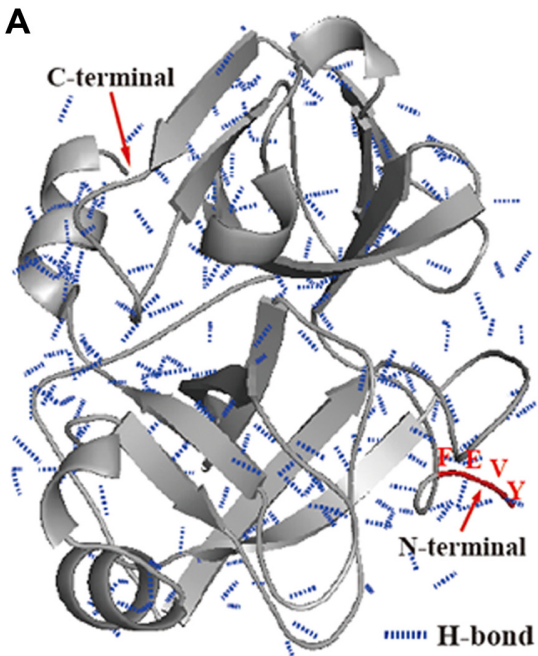

D

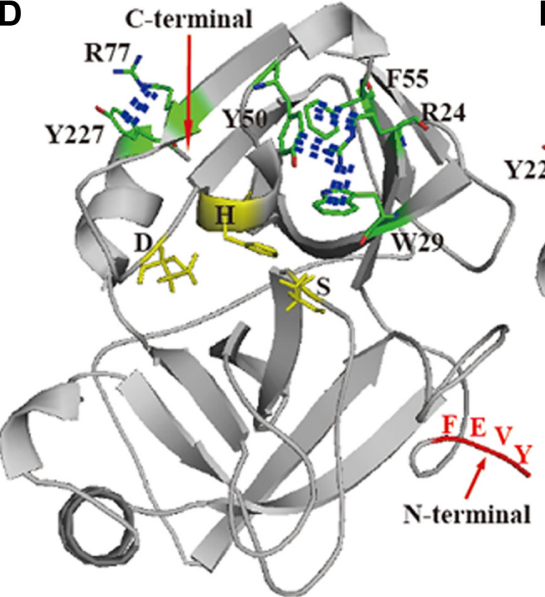

B
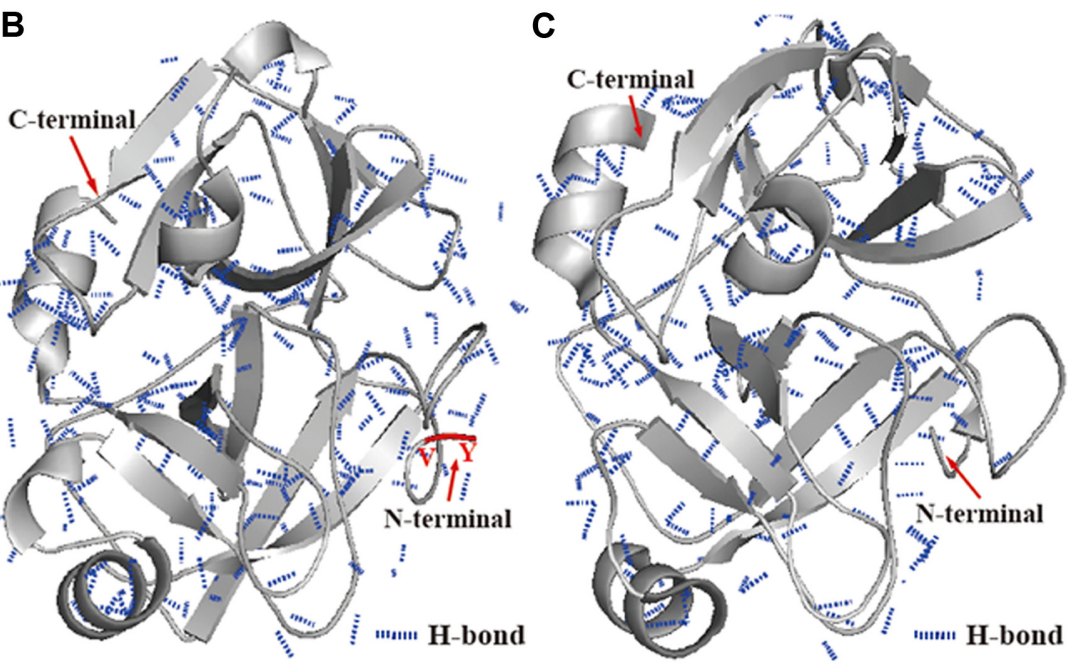

E

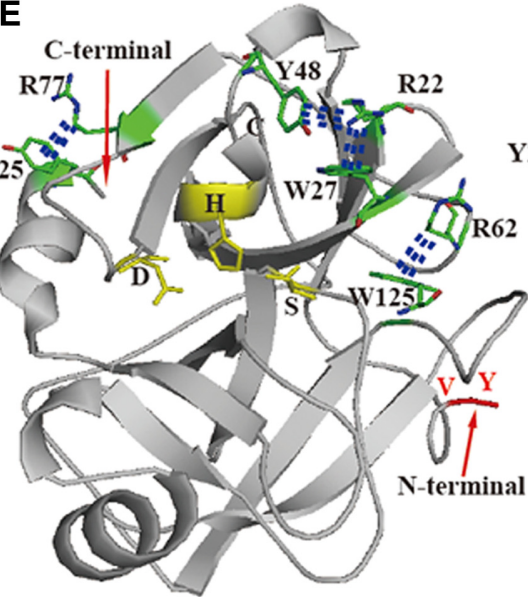

$\Xi \Xi \pi$-interaction

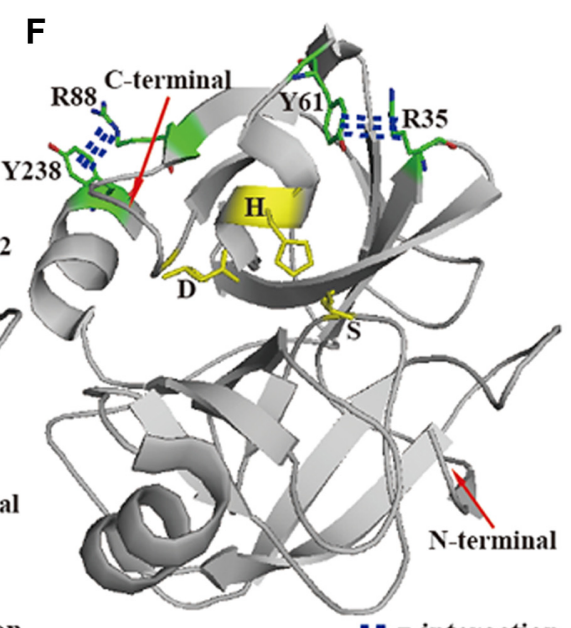

$\equiv \pi$-interaction

Fig. 4. Networks of the intramolecular $\mathrm{H}$ bonds and the cation $\pi$-interactions in wild-type FOT and the recombinants TE and TS with the peptides YVEF and YV, respectively.

(A) Network of intramolecular H bonds in TE; (B) Network of intramolecular H bonds in TS; (C) Network of intramolecular H bonds in wild-type FOT; (D) Cation $\pi$-interactions of TE; (E) Cation $\pi$-interactions of the recombinant TS; (F) Cation $\pi$-interactions of wild-type FOT.

\section{Simulation and Analysis of the 3D-Model Structure}

To investigate the influence of the peptides YVEF and YV on trypsin properties from a protein structural perspective, 3D model structures of TE (Fig. 5A) and TS (Fig. 5B) were constructed based on the FOT crystal structure (PDB ID: 1xvo, Fig. 5C). There were no significant differences found between the wild-type and recombinant trypsins in their substrate binding regions and catalytic triads (Fig. 5). The catalytic triad of trypsin includes the residues Asp102, His42, and Ser180, of which the essential amino acid Asp102 residue matches the negative charges of the substrate peptide chains, determining the specific recognition and cleavage of trypsin [22]. Hence, the $\mathrm{Km}$ value was not much different among the wild-type and the recombinant trypsins, whereas the $k_{\text {cat }}$ value was increased because the structures with the peptide YVEF and YV exhibited shorter distances among D174-S180, G198-S180, and G208-S180, which improve the electron transfer rate and catalytic efficiency (Figs.5D-5F). In addition, the intramolecular hydrogen bonds and cation $\pi$-interactions of proteins were also analysed. As shown in Fig. 4, wild-type FOT had 304 intramolecular hydrogen bonds and only 3 cation $\pi$-interactions. However, in case of the TE with the amino acids YVEF, intramolecular hydrogen bonds and cation $\pi$ - 
A

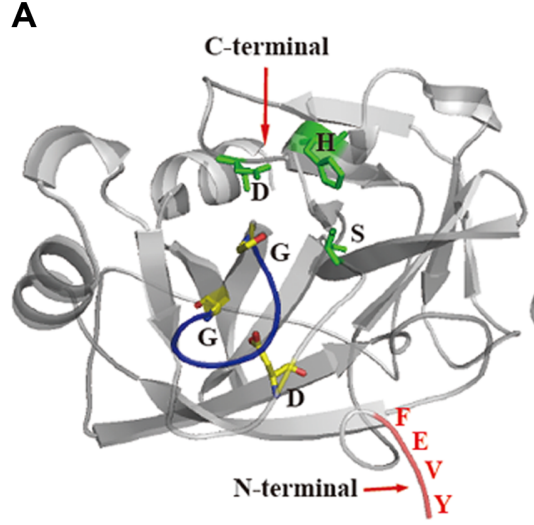

D

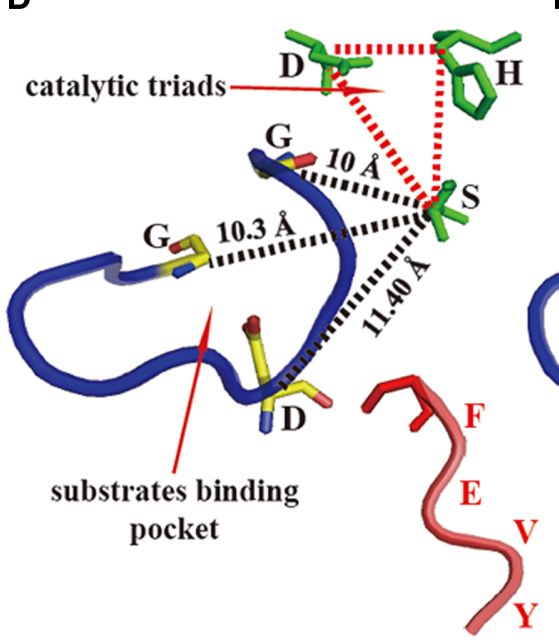

B

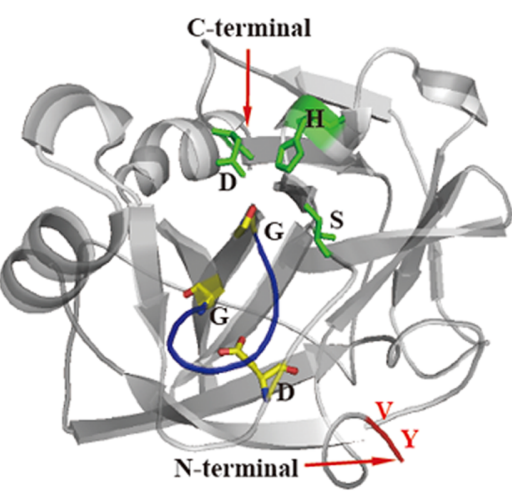

$\mathbf{E}$

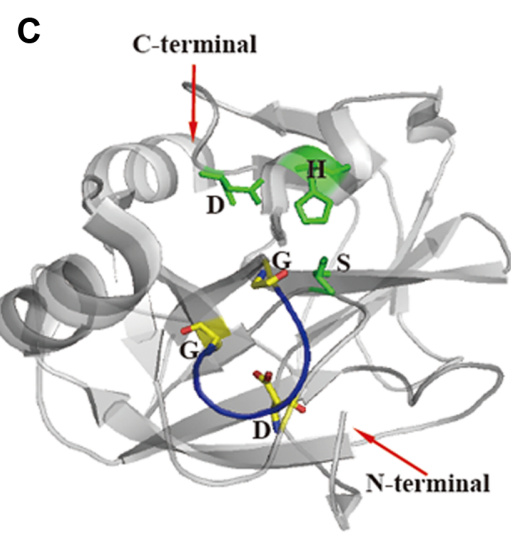

$\mathbf{F}$
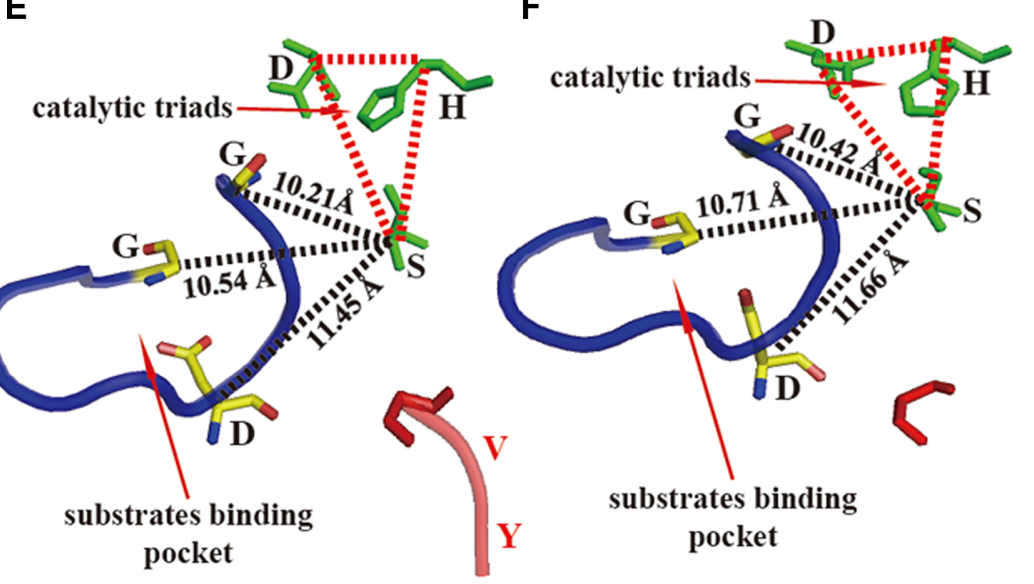

Fig. 5. Construction of the 3D model structure of the recombinant Fusarium oxysporum trypsins TE and TS with the software NAMD.

The crystal structure of Fusarium oxysporum trypsin (FOT) was used as the template. (A) Simulated structure of the recombinant TE; (B) Simulated structure of the recombinant TS; (C) Crystal structure of wild-type FOT; (D) $\mathrm{C}_{\alpha}$-distances of the substrate binding pocket and catalytic triad in the recombinant TE; (E) $\mathrm{C}_{\alpha}$-distances of the substrate binding pocket and catalytic triad in the recombinant TS; (F) $\mathrm{C}_{\alpha}$-distances of the substrate binding pocket and catalytic triad in wild-type FOT.

interactions were increased to 385 and 8 . Meanwhile, the TS with the peptide residues $\mathrm{YV}$, contained 370 intramolecular hydrogen bonds and 6 cation $\pi$-interactions.

\section{Discussion}

Recently, the researchers reported that the amino acid residues of the $\mathrm{N}$-terminus notably increased the stability and the catalytic efficiency of the recombinant trypsin in P. pastoris GS115 [8, 17]. Thermal stabilization of trypsin from Streptomyces griseus has been shown to significantly increase at moderate temperatures $\left(40^{\circ} \mathrm{C}\right)$, presumably because of shifts in the N-terminal peptide YVEF [7]. Here, the thermal stability and tolerance of TE and TS was found better than that of wild-type FOT at $40^{\circ} \mathrm{C}$ and $50^{\circ} \mathrm{C}$ (Figs. 3A and 3B). The increased thermal stability of the recombinant proteins may have been due to the fusion of the peptides to the $\mathrm{N}$-terminus of mature trypsin in P. pastoris, which affects their structure [7]. Moreover, hydrogen bonds do make a contribution to enzyme stability. It has been shown that the positive correlations between increasing number of hydrogen bonds and temperature stability were displayed [22]. Similarly, the average contributions of hydrophobic interactions and hydrogen bonds to stability were $60 \pm 4 \%$ and $40 \pm 4 \%$, respectively, based on the analysis of 22 proteins [23]. Indeed, as shown in Figs. 4A-4C), the introduction of the peptide YVEF to FOT increased the number of hydrogen 
bonds from 304 to 385, and the number of hydrogen bonds when adding the peptide YV to FOT also increased from 304 to 370 , which improved the stability of TS at high temperatures. These results were consistent with the previously reported studies [7, 8]. Meanwhile, cation $\pi$-interactions also play an important role in the thermal stability of proteins through electrostatic interaction, as has been previously reported [22]. Similarly, in Figs. 4D-4F), peptides YVEF and YV added to trypsin increased the number of cation $\pi$-interactions from 3 to 8 and from 3 to 6 , respectively, enhancing the thermal stability of the recombinant enzymes. Therefore, the increased thermal stability of recombinant proteins may have been due to shifts in the hydrogen bonds and cation $\pi$-interactions.

MD simulations have been considered as a tool to increase the enzyme stability of haloalkane dehalogenase through identifying flexible regions from the protein structure [24]. The RMSD and the RMSF value mainly influence the Bfactor of the recombinant enzyme, which could be the factor related to the thermostability [25]. Research showed that less deviation of I163R and H135R RMSD implies reduced stability of protein. There is a positive correlation of the protein RMSD with the themostability of protein [24, 26]. The values of RMSD and RMSF were also calculated with the template of FOT (PDB.ID:1gdp), the RMSD and RMSF of TS is $0.9 \pm 0.2$ and $0.02141 \pm 0.00776$ respectively, and the RMSD and RMSF of TE is $1.0 \pm 0.3$ and $0.02121 \pm 0.00826$ respectively (data not shown). These results were consistent with the results of the Fig. 3.

The recombinant trypsins increased $\mathrm{pH}$ tolerance, shown in Fig. 3D, is in line with the previous report that the replacement of APNP by YVEF, might be due to the engineered N-terminus containing the artificial peptide [7]. The Staphylococcus simulans protein with two amino acid residues (LK) was largely stable incubated for $24 \mathrm{~h}$ between $\mathrm{pH} 5$ and 12, in contrast to the others [27]. Other studies also demonstrated that the $\mathrm{pH}$ stability of $S$. simulans lipase was considerably affected after the insertion of four isoleucine residues at the $\mathrm{N}$-terminus area of the protein [28]. This supported our present finding that the different $\mathrm{N}$-terminal residues of the target protein contribute to its tolerance improvement of alkaline $\mathrm{pH}$.

The number of hydrogen bonds and cation $\pi$-interactions of TE and TS was found increased compared to that of wild-type FOT as shown in Fig. 4. This observation agrees with those of other studies which investigated the numbers of hydrogen bonds and cation $\pi$-interactions in trypsin from Streptomyces griseus, which increased by 251 to 312 and 1 to 5 in the presence of YVEF at the N-terminus, respectively [7]. It is confirmed that the same Lys $(\mathrm{K})$ could experience a greater number of cation $\pi$-interactions with several aromatic residues, such as Tyr (Y), Phe (F), Try (W), and His $(\mathrm{H})$. The amino acid $\mathrm{Y}$ does make a contribution to the stability of proteins via forming a greater number of cation $\pi$-interactions [29]. Due to the introduction of the amino acids $Y$ and $F$, the number of cation $\pi$-interactions was increased, which enhanced the stability of the target protein. Altering the $\mathrm{N}$-terminal amino acid residues in the target protein might help to stabilize trypsin structure, as has been reported [16].

Although there were no significant differences between the substrate binding pocket and catalytic triad areas, the short peptides at the N-terminus change the surrounding environment of the protein intramolecular structure [30, 31]. In comparison with FOT, the recombinant protein showed shorter distance among D174-S180, G198-S180, and G208-S180, which might be another reason underlying the improvement of catalytic efficiency, by raising the electron transfer rate[23]. The insertion of two residues (LK) at the N-terminus of Staphylococcus xylosus lipase caused a significant improvement in its catalytic properties, by 6-fold as compared to the wild-type enzyme [16]. The introduction of four isoleucine residues at the $\mathrm{N}$-terminus of $S$. simulans lipase (SSL) improved its specific activity (3fold) and catalytic efficiency, (2-fold) paralleling those of the recombinant enzyme [28], thus these research reports suggest that the $\mathrm{N}$-terminal residues modification of target proteins can improve their catalytic efficiency. These observations also suggest that a shorter distance between the substrate binding pocket and catalytic triad is another reason for the improved catalytic efficiency of TE and TS. Meanwhile, high numbers of hydrogen bonds and cation $\pi$-interactions also tend to improve Streptomyces griseus trypsin catalytic efficiency [7]. It is confirmed that the hydrogen bonds and cation $\pi$-interactions play dominant roles in enzyme stability $[29,32]$. As shown in Figs. 4A$4 \mathrm{C})$, the recombinant proteins had more hydrogen bonds and cation $\pi$-interactions. Therefore, the difference between the number of hydrogen bonds and cation $\pi$-interactions among these trypsin might have affected their catalytic properties.

On the other hand, the fusion of peptides to the $\mathrm{N}$ or $\mathrm{C}$ terminus of enzymes improves the expression of soluble proteins in microbial expression systems and affects their structure [16, 33, 34]. In this study, the introduction of peptides (YVEF and YV) to the protein increased its specific activity, catalytic efficiency, $\mathrm{pH}$ tolerance and thermal stability. In contrast, the fusion peptide for Staphylococcus 
xylosus lipase was the amino acid LK [16], whereas isoleucines were the optimal choice for Staphylococcus simulans lipase [28], and proline was optimal for glycosyl hydrolase family 10 ruminal xylanases [33]. Thus, the additive N-terminus residues of the target protein may be an effective strategy for a variety of proteins. However, this amino acid introduction strategy may not be suitable for all proteins. Therefore, it is necessary to rationally engineer peptides for the $\mathrm{N}$-terminus to improve the properties of a target protein.

In conclusion, we described an enzyme engineering strategy to enhance protein catalytic efficiency and stability by introduction of the non-natural peptides YVEF and YV to the N-terminus of FOT, and we compared the efficiencies of the resulting recombinant proteins with those of FOT as a wild-type protein. The results of this study indicated that the trypsins with added peptide residues had improved catalytic efficiency, specific activity, $\mathrm{pH}$ tolerance and thermal stability, especially the protein with the peptide YVEF. In addition, the analysis of the structure illustrated that the hydrogen bonds and cation $\pi$-interactions were also significantly increased. Although the introduction of the amino acids to trypsin improved its catalytic characteristics, amino acid introduction may be not suitable for all microbial enzymes, and the selection of amino acids will need to be verified for the specific enzyme. Based on this research, it might be viable to improve the properties of target enzymes by altering their N-terminal peptides. In future studies, we plan to design peptides for engineering other enzymes, which may help determine a general approach for the effective design of peptides for each enzyme.

\section{Acknowledgments}

We appreciate Zhang JunLi (Taishan Medical University) for her kindly help with the strain Fusarium oxysporum. This work was financially Supported by the Fundamental Research Funds for the Central Universities (Nos: lzujbky2015-87, lzujbky-2017-br01). It was also supported by the National Natural Science Foundation of China (Nos: 3160010090, 31470224) and Gansu province major science and technology projects (No: 17ZD2WA017).

\section{Conflict of Interest}

The authors have no financial conflicts of interest to declare.

\section{References}

1. Walsh K. 1970. Trypsinogens and trypsins of various species. Methods Enzymol. 19: 41-63.

2. Ling Z, Ma T, Li J, Du G, Kang Z, Chen J. 2012. Functional expression of trypsin from Streptomyces griseus by Pichia pastoris. J. Ind. Microbiol. Biotechnol. 39: 1651-1662.

3. Muhlia-Almazán A, Sánchez-Paz A, García-Carreño FL. 2008. Invertebrate trypsins: a review. J. Comp. Physiol. 178: 655-672.

4. Klomklao S. 2008. Digestive proteinases from marine organisms and their applications. Songklanakarin J. Sci. Technol. 30: 37-46.

5. Zugno LA. 1992. The effect of trypsin on soaking of salt cured hides. J. Am. Leather Chem. Assoc. 78: 207-220.

6. Torrissen K, Shearer K. 1992. Protein digestion, growth and food conversion in Atlantic salmon and Arctic charr with different trypsin-like isozyme patterns. J. Fish Biol. 41: 409-415.

7. Ling Z, Kang Z, Liu Y, Liu S, Chen J, Du G. 2014. Improvement of catalytic efficiency and thermostability of recombinant Streptomyces griseus trypsin by introducing artificial peptide. World J. Microbiol. Biotechnol. 30: 1819-1827.

8. Ling Z, Liu Y, Teng S, Kang Z, Zhang J, Chen J, et al. 2013. Rational design of a novel propeptide for improving active production of Streptomyces griseus trypsin in Pichia pastoris. Appl. Environ. Microbiol. 79: 3851-3855.

9. Zhang Y, Huang H, Yao X, Du G, Chen J, Kang Z. 2018. High-yield secretory production of stable, active trypsin through engineering of the N-terminal peptide and selfdegradation sites in Pichia pastoris. Bioresour. Technol. 247: 81-87.

10. Shu M, Shen W, Wang X, Wang F, Ma L, Zhai C. 2015. Expression, activation and characterization of porcine trypsin in Pichia pastoris GS115. Protein Exp. Purif. 114: 149-155.

11. Jónsdóttir G, Bjarnason JB, Gudmundsdóttir Á. 2004. Recombinant cold-adapted trypsin I from Atlantic codexpression, purification, and identification. Protein Exp. Purif. 33: $110-122$.

12. Pálsdóttir HM, Gudmundsdóttir Á. 2007. Expression and purification of a cold-adapted group III trypsin in Escherichia coli. Protein Exp. Purif. 51: 243-252.

13. Szilágyi L, Kénesi E, Katona G, Kaslik G, Juhász G, Gráf L. 2001. Comparative in vitro studies on native and recombinant human cationic trypsins cathepsin B is a possible pathological activator of trypsinogen in pancreatitis. J. Biol. Chem. 276: 24574-24580.

14. Chen J-M, Ferec C. 2000. Genes, cloned cDNAs, and proteins of human trypsinogens and pancreatitis-associated cationic trypsinogen mutations. Pancreas 21: 57-62.

15. Hohenblum H, Vorauer-Uhl K, Katinger H, Mattanovich D. 2004. Bacterial expression and refolding of human trypsinogen. J. Biotechnol. 109: 3-11.

16. Mosbah H, Horchani H, Sayari A, Gargouri Y. 2010. The insertion of (LK) residues at the N-terminus of Staphylococcus 
xylosus lipase affects its catalytic properties and its enantioselectivity. Process Biochem. 45: 777-785.

17. Kim J-H, Hong S-K. 2008. Overproduction of bacterial trypsin in streptomyces-optimization for streptomyces griseus trypsin production by recombinant streptomyces. Microbiol. Biotechnol. Lett. 36: 28-33.

18. Barata RA, Andrade MH, Rodrigues RD, Castro IM. 2002. Purification and characterization of an extracellular trypsinlike protease of Fusarium oxysporum var. lini. J. Biosci. Bioeng. 94: 304-308.

19. Rypniewski WR, Hastrup S, Betzel C, Dauter M, Dauter Z, Papendorf G, et al. 1993. The sequence and X-ray structure of the trypsin from Fusarium oxysporum. Protein Eng. 6: 341-348.

20. Phillips JC, Braun R, Wang W, Gumbart J, Tajkhorshid E, Villa E, et al. 2005. Scalable molecular dynamics with NAMD. J. Comput. Chem. 26: 1781-1802.

21. Justin PG, Dennis AD. 1999. Cation- $\pi$ interactions in structural biology. Chem. Biochem. 96: 9459-9464.

22. Robert MS, Anthony AK, John LC. 1977. Mechanism of zymogen activation. 6: 177-193.

23. Pace CN, Fu H, Fryar KL, Landua J, Trevino SR, Shirley BA, et al. 2011. Contribution of hydrophobic interactions to protein stability. J. Mol. Biol. 408: 514-528.

24. Purmonen M, Valjakka J, Takkinen K, Laitinen T, Rouvinen J. 2007. Molecular dynamics studies on the thermostability of family 11 xylanases. Protein Eng. Des. Sel. 20: 551-559.

25. Yin J, Bowen D, Southerland WM. 2006. Barnase thermal titration via molecular dynamics simulations: detection of early denaturation sites. J. Mol. Graph. Model. 24: 233-243.

26. Priya Doss CG, Nagasundaram N, Chakraborty C, Chen L Zhu H. 2013. Extrapolating the effect of deleterious nsSNPs in the binding adaptability of flavopiridol with CDK7 protein: a molecular dynamics approach. Hum. Genomics 7: 1-15.

27. Horchani H, Mosbah H, Salem NB, Gargouri Y, Sayari A. 2009. Biochemical and molecular characterisation of a thermoactive, alkaline and detergent-stable lipase from a newly isolated Staphylococcus aureus strain. J. Mol. Catal. B Enzym 56: 237-245.

28. Ouertani S, Frikha F, Horchani H, Ben Salem N, Gargouri Y, Sayari A. 2012. The insertion of four residues Isoleucines at the N-terminus of Staphylococcus simulans lipase affects its catalytic and biochemical properties. J. Mol. Catal. B Enzym 82: 1-7.

29. Gromiha MM, Thomas S, Santhosh C. 2002. Role of cation- $\pi$ interactions to the stability of thermophilic proteins. Prep. Biochem. Biotechnol. 32: 355-362.

30. Kraut J. 1977. Serine proteases: structure and mechanism of catalysis. Annu. Rev. Biochem. 46: 331-358.

31. Page MJ, Wong SL, Hewitt J, Strynadka NCJ, MacGillivray RTA. 2003. Engineering the primary substrate specificity of Streptomyces griseus trypsin. Biochemistry 42: 9060-9066.

32. Nick Pace C, Scholtz JM, Grimsley GR. 2014. Forces stabilizing proteins. FEBS Lett. 588: 2177-2184.

33. Zhongyuan L, Xianli X, Heng Z, Peilong Y, Huiying L, Junqi $Z$, et al. 2014. A C-terminal proline-rich sequence simultaneously broadens the optimal temperature and $\mathrm{pH}$ ranges and improves the catalytic efficiency of glycosyl hydrolase family 10 ruminal xylanases.

34. Haiquan Y, Xinyao L, Long L, Jianghua L, Hyun-dong S, Rachel RC, et al. 2013. Fusion of an oligopeptide to the $\mathrm{N}$ terminus of an alkaline amylase from alkalimonas amylolytica simultaneously improves the enzyme's catalytic efficiency, thermal stability, and resistance to oxidation. AEM 79: 30493058. 